\title{
Dopamine exacerbates mutant Huntingtin toxicity via oxidative- mediated inhibition of autophagy in SH-SY5Y neuroblastoma cells: Beneficial effects of anti-oxidant therapeutics
}

\author{
Chiara Vidoni ${ }^{a}$, Andrea Castiglioni ${ }^{a}$, Christian Seca ${ }^{a}$, Eleonora Secomandi a ,

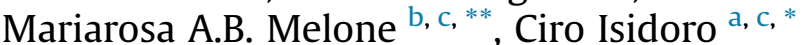 \\ a Laboratory of Molecular Pathology, Department of Health Sciences, Università del Piemonte Orientale "A. Avogadro", Novara, Italy \\ ${ }^{\mathrm{b}} 2^{\circ}$ Division of Neurology, Department of Medical Surgical, Neurological, Metabolic Sciences, and Aging, Second University of Naples, Naples, Italy \\ ${ }^{\mathrm{c}}$ InterUniversity Center for Research in Neurosciences, Second University of Naples, Naples, Italy
}

\section{A R T I C L E I N F O}

\section{Article history:}

Received 1 September 2016

Received in revised form

31 October 2016

Accepted 1 November 2016

Available online 11 November 2016

\section{Keywords:}

Huntington

Parkinson

Dopaminergic neurons

Autophagy

Anti-oxidant

Neurodegeneration

\begin{abstract}
A B S T R A C T
Neuronal cell death in Huntington's Disease (HD) is associated with the abnormal expansions of a polyglutamine (polyQ) tract in the huntingtin protein ( $\mathrm{Htt}$ ) at the $\mathrm{N}$-terminus that causes the misfolding and aggregation of the mutated protein ( $\mathrm{mHtt}$ ). Autophagy-lysosomal degradation of $\mathrm{Htt}$ aggregates may protect the neurons in HD. HD patients eventually manifest parkinsonian-like symptoms, which underlie defects in the dopaminergic system. We hypothesized that dopamine (DA) exacerbates the toxicity in affected neurons by over-inducing an oxidative stress that negatively impinges on the autophagy clearance of $\mathrm{mHtt}$ and thus precipitating neuronal cell death. Here we show that the hyper-expression of mutant ( $>113 / 150)$ polyQ Htt is per se toxic to dopaminergic human neuroblastoma SH-SY5Y cells, and that DA exacerbates this toxicity leading to apoptosis and secondary necrosis. DA toxicity is mediated by ROS production (mainly anion superoxide) that elicits a block in the formation of autophagosomes. We found that the pre-incubation with N-Acetyl-L-Cysteine (a quinone reductase inducer) or Deferoxamine (an iron chelator) prevents the generation of ROS, restores the autophagy degradation of mHtt and preserves the cell viability in SH-SY5Y cells expressing the polyQ Htt and exposed to DA.

The present findings suggest that DA-induced impairment of autophagy underlies the parkinsonism in HD patients. Our data provide a mechanistic explanation of the DA toxicity in dopaminergic neurons expressing the $\mathrm{mHtt}$ and support the use of anti-oxidative stress therapeutics to restore protective autophagy in order to slow down the neurodegeneration in HD patients.
\end{abstract}

(c) 2016 Elsevier Ltd. All rights reserved.

\section{Introduction}

Huntington's Disease (HD) is a devastating autosomal dominant neurodegenerative condition characterized by neuronal loss in striatum (particularly of medium-sized spiny neurons (MSNs)), deep layers of the cortex and, when disease progresses, in hypothalamus and hippocampus and other brain regions (Vonsattel

\footnotetext{
* Corresponding author. Dipartimento di Scienze della Salute, Università “A. Avogadro", Via P. Solaroli 17, 28100 Novara, Italy. Tel: +39 0321660507 ; fax: +39 0321620421.

** Corresponding author. $2^{\circ}$ Division of Neurology, Dipartimento di Scienze Mediche, Chirurgiche, Neurologiche, Metaboliche e dell'Invecchiamento, Seconda Università di Napoli, Scuola di Medicina, Via Sergio Pansini, 5, 80131 Napoli, Italy. Tel: +39 081 5666810; fax: +390815666808.

E-mail addresses: marina.melone@unina2.it (M.A.B. Melone), ciro.isidoro@med. uniupo.it (C. Isidoro).
}

et al., 1985). Pathogenesis and progression of HD are strictly correlated with the presence in the affected neurons of cytoplasmatic aggregates and nuclear inclusions of the mutated form of the protein Huntingtin ( $\mathrm{Htt})$ and of its $\mathrm{N}$-terminal fragments (DiFiglia et al., 1997; Soto, 2003; Melone et al., 2005). Mutant Htt $(\mathrm{mHtt})$ is characterized by abnormal expansions of a polyglutamine (polyQ) tract to more than 37 Qs (Rubinsztein, 2002). While normal $\mathrm{Htt}$ has anti-apoptotic function, $\mathrm{mHtt}$ is neurotoxic. The N-terminal fragments of around 150 residues containing the polyQ stretch arising from the proteolytic processing by proteasomes, calpain and aspartyl proteases are even more toxic than full-length Htt (DiFiglia et al., 1997; Ratovitski et al., 2007, 2009; Rossetti et al., 2008). HD patients typically suffer from progressive motor and cognitive impairments, loss of self and spatial awareness, depression, dementia and anxiety over the course of 10-20 years before death. Alteration in dopamine (DA) neurotransmission is clearly involved in motor 
and cognitive symptoms of HD patients (Cepeda et al., 2014). Striatal and cortical loss of DA receptors in early stage of HD patients has been correlated with early cognitive decline, such as attention, executive function, learning and memory (Bäckman and Farde, 2001). The level of DA is elevated in the early stage of the disease (characterized by the chorea), while it decreases in the late stage when Parkinson-like symptoms (akinesia) become apparent (Garrett and Soares-da-Silva, 1992; Kish et al., 1987; Chen et al., 2013). Indeed, the level of DA in HD patients with parkinsonism resembles that of Parkinson Disease patients (Chen et al., 2013). DA is normally present in the striatum at elevated concentration, and is not harmful to normal neurons. However, DA is per se an excitotoxic neurotransmitter that triggers oxidative stress and may cause neuronal cell death (Jakel and Maragos, 2000). In vitro, DAmediated oxidative stress was shown to induce apoptosis of striatal MSNs derived from transgenic R6/2 mice, an animal model of HD (Petersén et al., 2001a). It is possible that DA and glutamate synergize for the production of reactive oxygen species (ROS), so enhancing the toxicity of mHtt in MSNs (Cepeda et al., 2014).

The autophagy-lysosomal proteolytic system plays a protective role in HD by removing Htt aggregates (Sarkar and Rubinsztein, 2008). Dysfunctional regulation of this proteolytic system is consistently found in neurodegenerative disorders (Vidoni et al., 2016). Drugs able to increase the level of autophagy promote the clearance of Htt aggregates and relief the clinical symptom in 'in vivo' model of HD (Rubinsztein, 2006; Sarkar et al., 2007, 2008; Roscic et al., 2011). Autophagy has been reported to be up-regulated in post mortem striatum regions of HD patients (Cherra et al., 2010). Abnormal expression of autophagy-related (ATG) proteins in the neurons of a knock-in HD mouse model indicates that alteration of the autophagic flux is an early stress response to $\mathrm{mHtt}$ (Heng et al., 2010). The Htt protein itself can affect autophagy by directly interacting with SQSTM1/p62 (which tags the autophagy substrates) (Martinez-Vicente et al., 2010; Bjørkøy et al., 2005) and with ULK1 (which activates the BECLIN 1-PI3KC3 complex that triggers the autophagosome formation) (Rui et al., 2015), or by sequestering in the protein aggregate MTOR, a kinase that negatively regulates ULK1 (Ravikumar et al., 2004). Interestingly, autophagosomes accumulate in primary striatal neurons from HD mice expressing truncated mutant $\mathrm{Htt}$ following dopamine-induced oxidative stress (Petersén et al., 2001b).

What is the functional role of autophagy in dopaminergic neurons expressing the $\mathrm{mHtt}$ and what is the cytotoxic mechanism of DA that could underlie the onset of parkinsonism in HD patients remain however obscure. As an attempt to fill in this gap of knowledge, we investigated the molecular link between DAinduced oxidative stress and mHtt toxicity in relation to the activation of the autophagy pathway in an 'in vitro' model of parkinsonian HD. We found that DA-induced ROS production causes the death of dopaminergic human neuroblastoma SH-SY5Y cells expressing transgenic mHtt following the inhibition of autophagosome formation. Preventing ROS generation by N-Acetyl-LCysteine (an inducer of quinone reductase) or Deferoxamine (an iron chelator) restores the autophagy flux and the clearance of $\mathrm{mHtt}$, and saves the mHtt-expressing neuronal-like cells from DA toxicity. Thus, anti-ROS drugs able to restore autophagy could slow down the progression of HD and prevent the onset of parkinsonianlike symptoms in HD patients.

\section{Materials and methods}

\subsection{Cell culture and treatment}

Human dopaminergic neuroblastoma SH-SY5Y cells were obtained from the American Type Culture Collection (ATCC, Rockville,
MD) and cultured under standard culture condition $\left(37^{\circ} \mathrm{C} ; 95 \mathrm{v} / \mathrm{v} \%\right.$ air: $5 \mathrm{CO}_{2} \mathrm{v} / \mathrm{v} \%$ ) in 50\% Minimum Essential Medium (MEM, cod. M2279, Sigma-Aldrich Corp. St. Luis, MO, USA), 50\% Ham's F12 Nutrient Mixture (HAM, cod. N4888, Sigma-Aldrich Corp.) supplemented with $10 \%$ heat-inactivated fetal bovine serum (FBS, cod. ECS0180L, EuroClone S. p.A. Milan, Italy), $1 \% \mathrm{w} / \mathrm{v}$ of a penicillinstreptomycin solution (cod. P0781, Sigma-Aldrich Corp.) and $2 \mathrm{mM}$ di L-glutamine (cod. G7513, Sigma-Aldrich Corp.). The cells were seeded (starting density $70.000 / \mathrm{cm}^{2}$ ) on sterile Petri dishes or glass coverslip, as indicated, and allowed to adhere for 24-36 h prior to start any treatment. Excitotoxic treatment was performed with $100 \mu \mathrm{M}$ Dopamine (DA, cod. H8502, Sigma-Aldrich Corp. dissolved in sterilized $\mathrm{H}_{2} \mathrm{O}$ ). Apoptosis was inhibited with $20 \mu \mathrm{M}$ of the pancaspase inhibitor z-VAD (OMe)-fmk (z-VAD-fmk, cod. 260020-M005, Alexis Laboratories, San Diego, CA). The cells were preincubated $2 \mathrm{~h}$ with $2 \mathrm{mM}$ N-Acetyl-L-Cysteine (NAC, cod. A9165, Sigma-Aldrich Corp.) or $1 \mathrm{mM}$ Deferoxamine mesylate salt (DFO, D9533, Sigma-Aldrich Corp.) to prevent ROS generation. Chloroquine ( $\mathrm{ClQ} 30 \mu \mathrm{M}$, cod. C6628, Sigma-Aldrich Corp.) was used to inhibit autophagosome degradation. Pepstatin A (PstA, $100 \mu \mathrm{M}$, cod. P 5318, Sigma-Aldrich Corp.) was used as inhibitor of Cathepsin D.

\subsection{HD expression constructs and plasmid transfection}

The plasmids encoding for Htt (either wild-type or mutant) and for the polyQ tract (see Supplementary Fig. S1A) were generously provided by Prof. F. Persichetti (Università del Piemonte Orientale, Italy). (HD)N1-171Q21 and (HD)N1-171Q150 mammalian expression constructs in pcDNA3/Zeo $(+)$ encode the amino-terminal 171 amino acids of human Htt protein (Accession No. L12392, bp 314-823), with 21 and 150 glutamines, respectively. (HD)N1171Q21GFP and (HD)N1-171Q150GFP were created by inserting a fragment of pGreen Lantern-1, encoding a GFP-tag, in frame with the carboxy-terminus of the Htt sequence (Persichetti et al., 1999). Full length HD constructs Q21-FL ( $\mathrm{pC}_{3} \mathrm{~F}_{7} \mathrm{HD}$ Q21) and Q113-FL (FL $113 \mathrm{Q}$ HD CMV) encode the full length of human huntingtin protein, with 21 and 113 glutamines, respectively. The construct Q21-FL was created by inserting the FLAG-tag in frame with the aminoterminus of the full length human huntingtin protein.

The cells were transfected with the plasmids using the Lipofectamine 3000 Reagent (cod. L3000-015, Life Technologies Ltd, Paisley, UK) as indicated by the purchaser. Briefly, SH-SY5Y were plated in P35 Petri dish at $70.000 / \mathrm{cm}^{2}$ and let adhere $24 \mathrm{~h}$ before transfection. The DNA-Lipofectamine complexes were prepared in $500 \mu$ l of Opti-MEM I Reduced Serum Medium (cod. 11058021, Life Technologies Ltd) with $6 \mu \mathrm{g}$ of plasmid, $5 \mu \mathrm{l}$ of P3000 reagent and $7.5 \mu \mathrm{l}$ of Lipofectamine. After $6 \mathrm{~h}$ of incubation, the transfection medium was replaced with a serum-containing culture medium (10\% FBS), and the cells were cultivated for further $21 \mathrm{~h}$ to allow for maximal expression of the transgenic protein prior to any treatment.

\subsection{Assessment of cell proliferation, cell viability and cell toxicity}

Cell culture growth was assessed by cell counting of adherent viable (trypan blue-excluding) cells, and the doubling time (Dt) was calculated using the software Doubling Time Online Calculator (http://www.doubling-time.com/compute.php).

To test cell viability, the cells adherent on coverslips were labeled with CellTracker TM (CellTracker TMBlue-CMAC 7-amino4-chloromethylcoumarin; cod. C2110, Life Technologies Ltd), and the blue fluorescence, an indicator of the mitochondrial respiratory activity, was immediately imaged under the fluorescence microscope Leica DMI6000 (Ekkapongpisit et al., 2012; Cagnin et al., 2012). 
At least five fields randomly chosen in each coverslip were examined in three separate experiments and quantitated with ImageJ by two independent investigators. Representative images are shown.

Necrotic cells were identified on the basis of trypan blue staining or propidium iodide (PI; cod. P4170, Sigma-Aldrich Corp.) labeling (Castino et al., 2007, 2010). Hypodiploid (Sub-G1 peak) PIlabeled cells were evaluated by cytofluorimetry and assumed as apoptotic. At least 5.000 cells were analyzed using a FacScan flow cytometer (Becton Dickinson, Mountain View, CA, USA) equipped with a $488 \mathrm{~nm}$ argon laser. Data were elaborated with the winMDI software.

Mitochondrial membrane integrity was assayed by Rhodamine 123 (cod. R8004, Sigma-Aldrich Corp.; 50 nM, 10 min in the dark at $37^{\circ} \mathrm{C}$ ) fluorescence retention test. Mitochondrial ROS (essentially anion superoxide) were assayed by staining living cells with MitoSOX (cod. M36008, Life Technologies Ltd; $5 \mu \mathrm{M}$ ) fluorescence staining (Castino et al., 2011).

\subsection{Protein expression analysis}

Cell homogenates were collected in RIPA-buffer containing phosphatase and protease inhibitors. Protein extracts were mixed with $5 \times$ sample loading buffer and boiled for $5 \mathrm{~min}$ at $95^{\circ} \mathrm{C}$. Protein content was determined using the Bradford reagent (Cod. B6916, Sigma-Aldrich Corp.), as previously (Follo et al., 2011). About $30 \mu \mathrm{g}$ of protein was separated by electrophoresis on a $15 \%$ and $6 \%$ (depending on the molecular size of the protein of interest) SDSPAGE gel and then transferred to PVDF membrane (Bio-Rad, Hercules, CA, USA). PageRuler Prestained Protein Ladder (Cod. 26616, Thermo Fisher Scientific Inc. Waltham, MA, USA) and Spectra Multicolor High Range Protein Ladder (cod. 26625, Thermo Fisher Scientific Inc.) were used as Molecular weight markers. The membranes were blocked with 5\% non-fat milk in Phosphate Buffer Saline (PBS) with $0.2 \%$ Tween-20 for $1 \mathrm{~h}$ at room temperature and incubated with specific primary antibodies overnight at $4{ }^{\circ} \mathrm{C}$. $\beta$ tubulin was used as homogenate protein loading control. Immunocomplexes were revealed by incubation with an appropriate peroxidase-conjugated secondary antibody (cod. 170515, 1706516, Bio-Rad), followed by peroxidase-induced chemiluminescence reaction (cod. NEL103E001 EA, PerkinElmer, Waltham, MA, USA). Intensity of the bands was estimated by densitometry (Quantity One Software, Bio-Rad or ImageJ software).

\subsection{Immunofluorescence staining}

Cells plated and let adhere on glass coverslip were fixed in cold methanol, permeabilized with $0.2 \%$ Triton-PBS and then re-fixed with methanol. After washing with PBS, the coverslips were incubated with the specific primary antibodies dissolved in $0.1 \%$ TritonPBS plus $4 \%$ FBS overnight at $4{ }^{\circ} \mathrm{C}$. The following day, the immunocomplexes were revealed by secondary antibodies, either IRIS-2 (green fluorescence) - or IRIS-3 (red fluorescence)-conjugated goatanti-rabbit IgG or goat-anti-mouse IgG (cod. 2W5-08, 2W5-07, 3W5-08, 3W5-07, Cyanine Technology SpA, Turin, I) dissolved in $0.1 \%$ Triton-PBS plus $4 \%$ FBS for $1 \mathrm{~h}$ in the dark. Fluorescence counterstaining of the nuclei was performed with DAPI $(4,6-$ diamidino-2-phenylindole, cod. 32670, Sigma-Aldrich Corp.). Finally, the coverslips were washed with $0.1 \%$ Triton-PBS and mounted onto glasses using SlowFade (cod. S36936, Life Technologies Ltd), and the images were acquired under the fluorescence microscope Leica DMI6000.

\subsection{Primary antibodies used for western blotting and immunofluorescence}

The following primary antibodies were used to identify Htt (see Supplementary Fig. S1B for the epitope recognized): monoclonal mouse anti-HTT (1:1000 for immunoblotting and 1:500 for immunofluorescence, cod. MAB2166, EMD Millipore Corporation, Billerica, MA, USA); monoclonal mouse anti-HTT1C2 Ms X Polyglutamine (1:1000 for immunoblotting, cod. MAB1574, EMD Millipore Corporation). Other antibodies used were: rabbit antiSQTM1/p62 (1:500, cod. 8025, Cell Signaling Technology, Danvers, MA U.S.A.), rabbit anti-LC3B (1:1000, cod. L7543, Sigma Aldrich Corp.), rabbit anti-Cathepsin D (1:100 for immunofluorescence, produced in our laboratory (Erdmann et al., 2007); mouse antiLAMP1 (1:1000 for immunofluorescence, cod. 555798, Becton, Dickinson and Company, New Jersey, NJ, USA), mouse anti- $\beta$ tubulin (1:1000 for immunoblotting, cod. T5201, Sigma Aldrich Corp.), mouse anti-p21 (1:100, cod. sc-817, Santa Cruz Biotechnology Inc. Dallas, TX, USA), polyclonal rabbit anti-MKI67 (Ki-67, 1:100 for immunostaining, cod. HPA001164, ATLAS-Sigma Prestige Antibodies, Sigma-Aldrich Corp.), mouse anti-GFP (1:1000, cod. 632381, Living Color Monoclonal Antibody (JL-8), Clontech Laboratories Inc. Mountain View, CA U.S.A.).

\subsection{Statistical analysis}

Image processing and data quantification of the intensity of fluorescence (INT. DEN) images were performed with the software ImageJ 1.48v (http://imagej.nih.gov/ij/). At least five randomly chosen fields were analyzed. Fluorescence Intensity (INT. DEN) is given in arbitrary units as an average value per cell in the selected representative fields. Quantification of fluorescence was performed on single channel (either red or blue) in the case of MitoSOX and Cell Tracker staining, or on the two-channels merge (green + red $=$ yellow) in the case of double-staining to estimate the co-localization of two markers.

Densitometry of Western Blot bands was performed with the Quantity One-4.5.0 software (Bio-Rad).

Statistical analysis was performed with the GraphPad Prism 5 software. Tukey's test after one-way ANOVA analysis and $t$-test (paired, two-tailed) were employed. Significance was taken as follow: ${ }^{* * *} \mathrm{p}<0.001 ;{ }^{* *} \mathrm{p}<0.01 ;{ }^{*} \mathrm{p}<0.05$.

All data have been reproduced at least three times in separate and independent experiments, and data are reported as average \pm S.D.

\section{Results}

\subsection{The polyQ tract negatively affects cell viability and cell proliferation of dopaminergic SH-SY5Y cells}

SH-SY5Y cells transfected with the plasmid empty (SHAM) or encoding the wild-type full length $\mathrm{Htt}$ (Q21-FL) or the mutant polyQ Htt (Q113-FL, $\mathrm{mHtt}$ ) expressed the protein at relatively high level for up to $72 \mathrm{~h}$ (Supplementary Fig. S2A). However, the transgenic expression of the chimeric GFP-tagged N-terminal fragments bearing the Q21 tract or the mutant Q150 tract (N171Q21-GFP and N171Q150-GFP, respectively) was maximal at $24 \mathrm{~h}$ posttransfection and thereafter declined (Supplementary Fig. S2A). Therefore, in the next experiments, the phenomena were described at $24-48 \mathrm{~h}$ post-transfection. The transgenic expression of Q113-FL $\mathrm{Htt}$, but not that of the Q21-FL Htt (considered as the normal wildtype $\mathrm{Htt}$ ), affected cell viability and cell reproduction (Dt was increased) of dopaminergic human neuroblastoma SH-SY5Y cells, as assayed by counting the viable cells, the trypan blu-stained cells 
A)

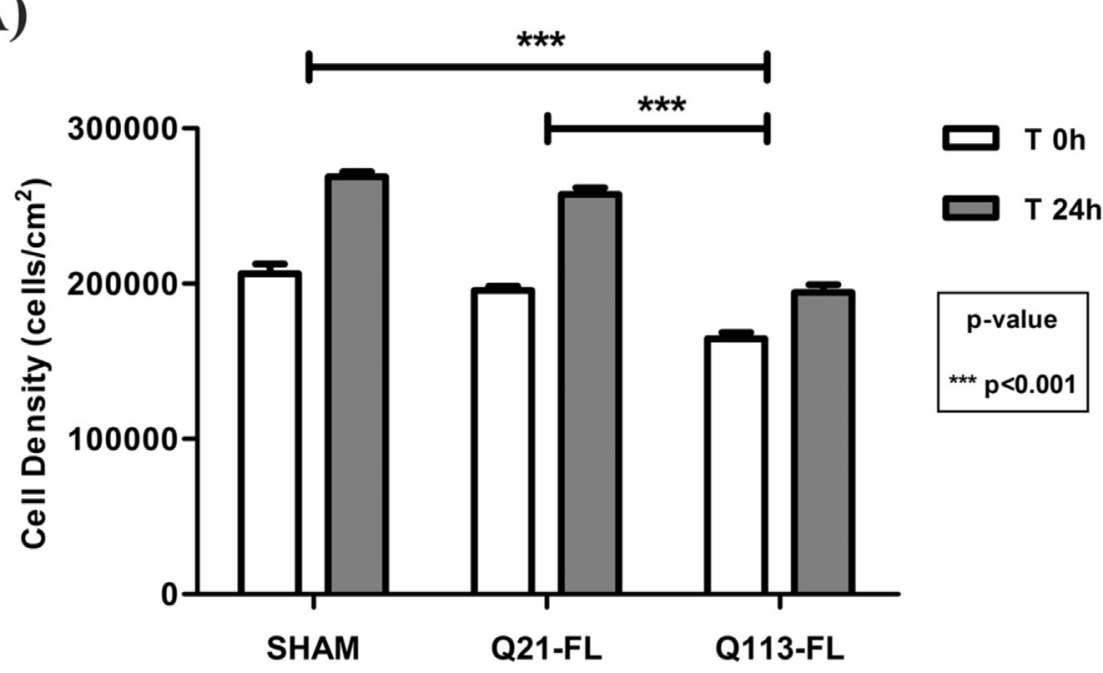

B)

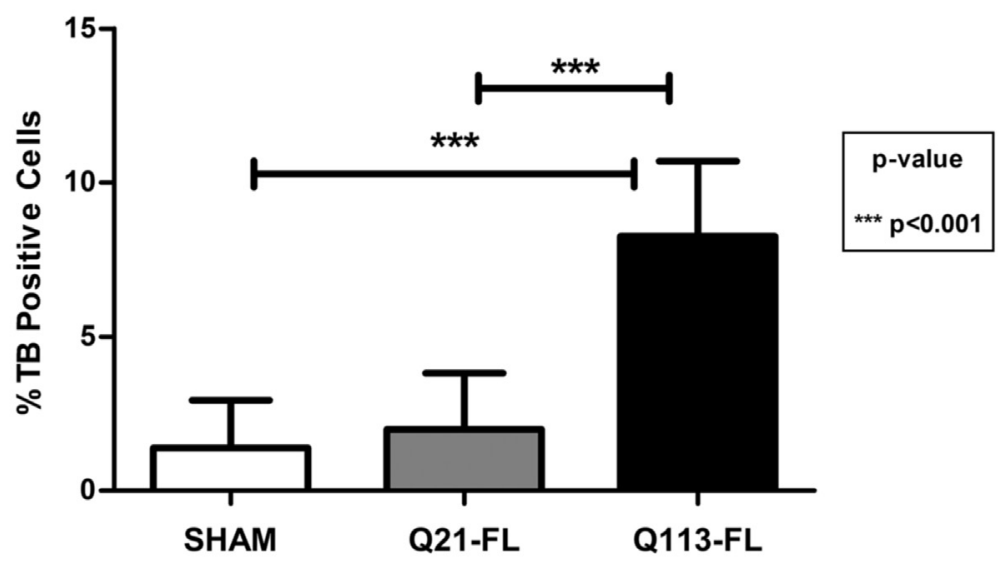

C)

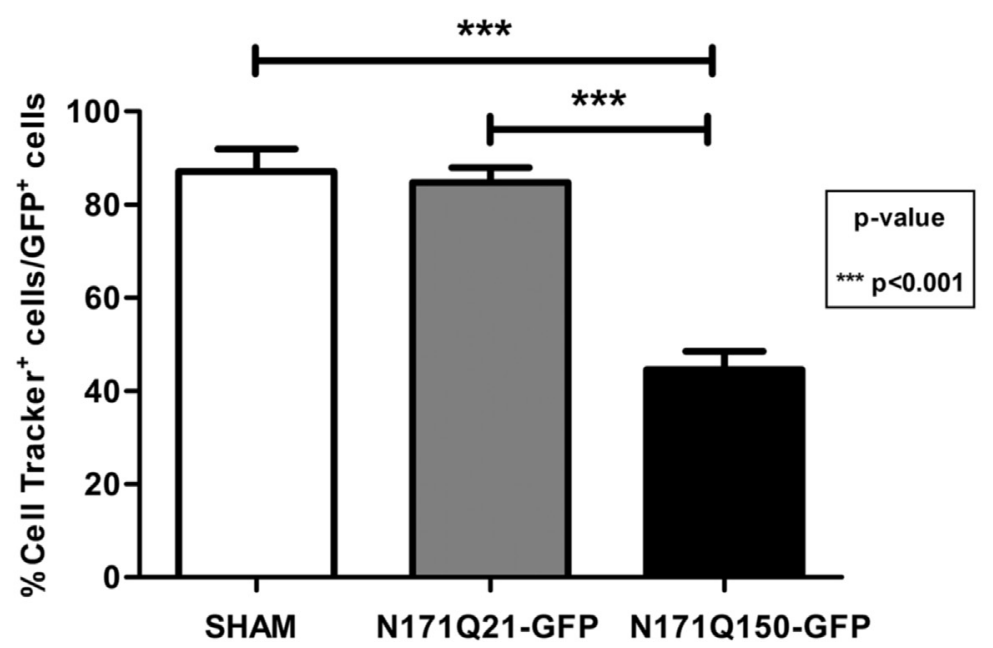

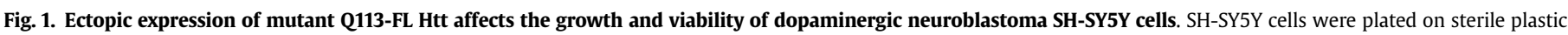

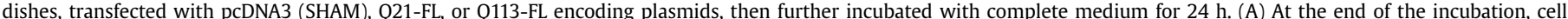

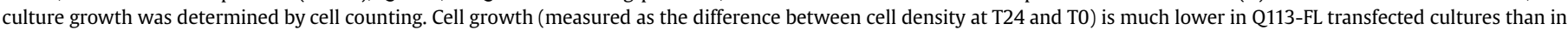

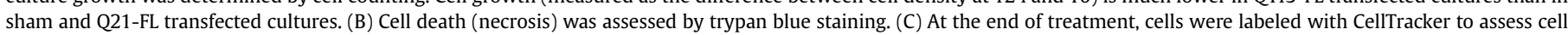

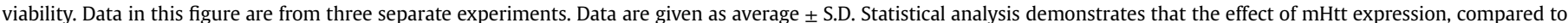
that of sham and normal Htt, on cell culture growth, necrosis and cell survival is significant. 
and the CellTracker-positive cells (Fig. 1). At $48 \mathrm{~h}$ post-transfection, the doubling time of SH-SY5Y cultures expressing the Q113-FL Htt was two-folds longer than that of SHAM or Q21-FL Htt transfected counterparts, and the final cell density was reduced by some $30 \%$ (data not shown). Consistently, immunofluorescence staining showed an increased expression of p21 and a decreased expression of Ki-67 in the cells expressing the Q113-FL (data not shown). To see whether the polyQ tract was responsible for such toxic effect, we assayed cell viability upon transfection with the N-terminal portion bearing the Q21 or the Q150 tract. As assayed by CellTracker staining, the cells expressing the N171Q150-GFP protein showed a reduced vitality, while SHAM-GFP and N171Q21-GFP transfected cells were fully viable (Figs. S2B and S2C). Taken together, we conclude that the over-expression of mHtt with a polyQ tract is per se toxic to dopaminergic neuroblastoma cells.

\subsection{The ectopic hyper-expression of Q113-FL mutant Huntingtin sensitizes dopaminergic neuroblastoma cells to Dopamine toxicity}

We then tested the hypothesis that dopaminergic cells expressing the mutant Htt are more frail and sensitive to DA excitotoxicity. The SH-SY5Y cells were transfected with the plasmids coding for the wild-type or the mutant polyQ Htt and their viability was assessed after a $24 \mathrm{~h}$ exposure to DA. A parallel set of cells was pre-incubated with the pan-caspase inhibitor z-VAD-fmk in order to assess the possible onset of apoptosis. Based on cytofluorometry analysis, upon exposure to DA the fraction of SubG1 cells (considered as apoptotic) was increased in the cultures expressing the Q113-FL mHtt, compared to SHAM and Q21-FL Htt cultures, and this toxic effect was not observed when the caspases were inhibited (data not shown). Consistently, cleaved active caspase 3 was detected in the cells expressing the Q113-FL mHtt exposed to DA (not shown). Upon exposure to DA, the proportion of necrotic (trypan blu positive) cells increased, and in parallel the number of adherent viable cells decreased, in the cultures transfected with the Q113-FL mHtt plasmid compared to that of SHAM or Q21-FL transfected cultures (Fig. 2). To see whether the polyQ tract is itself toxic and to ensure that indeed necrosis occurred in the transfected cells, the SH-SY5Y cells were transfected with the plasmid encoding for the GFP-tagged $\mathrm{N}$-terminal Htt bearing the Q21 or the Q150 and then necrotic cells were revealed by PI staining (the cells being not fixed). Representative images of this experiment are shown Fig. S3, and its quantitation is illustrated in the graph of Fig. 2C. It is apparent that cell necrosis occurs in the cells expressing the $\mathrm{N}$-terminal polyQ tract of $\mathrm{Htt}$ upon exposure to DA, and that such death can be prevented by the pan-caspase inhibitor, indicating that necrosis is secondary to apoptosis.

\subsection{Dopamine impairs autophagy and mutant Huntingtin degradation}

Autophagy-mediated clearance of aggregates-prone mutant proteins preserves the neuronal vitality and function (Castino et al., 2005a; Sarkar et al., 2007; Heiseke et al., 2009). The mHtt itself has been reported to negatively affect the autophagy process (Martinez-Vicente et al., 2010; Rui et al., 2015). First, we checked whether in our experimental model Htt was indeed targeted to the autophagy-lysosomal system. The lysosomal protease cathepsin D (CD) that has been shown to effect the proteolysis of Htt (Qin et al., 2003). In the experiment, we have therefore included Pepstatin A, its specific inhibitor. The images in Fig. $3 \mathrm{~A}$ and $\mathrm{B}$ show that both the 'wild-type' and the mutant Htt co-localize with LC3 and with CD, markers of autophagosomes and lysosomes, respectively. It is also apparent that the fluorescence staining of the mutant Htt (Q113-FL) increases in the cells exposed to Pepstatin A. Taken together, these
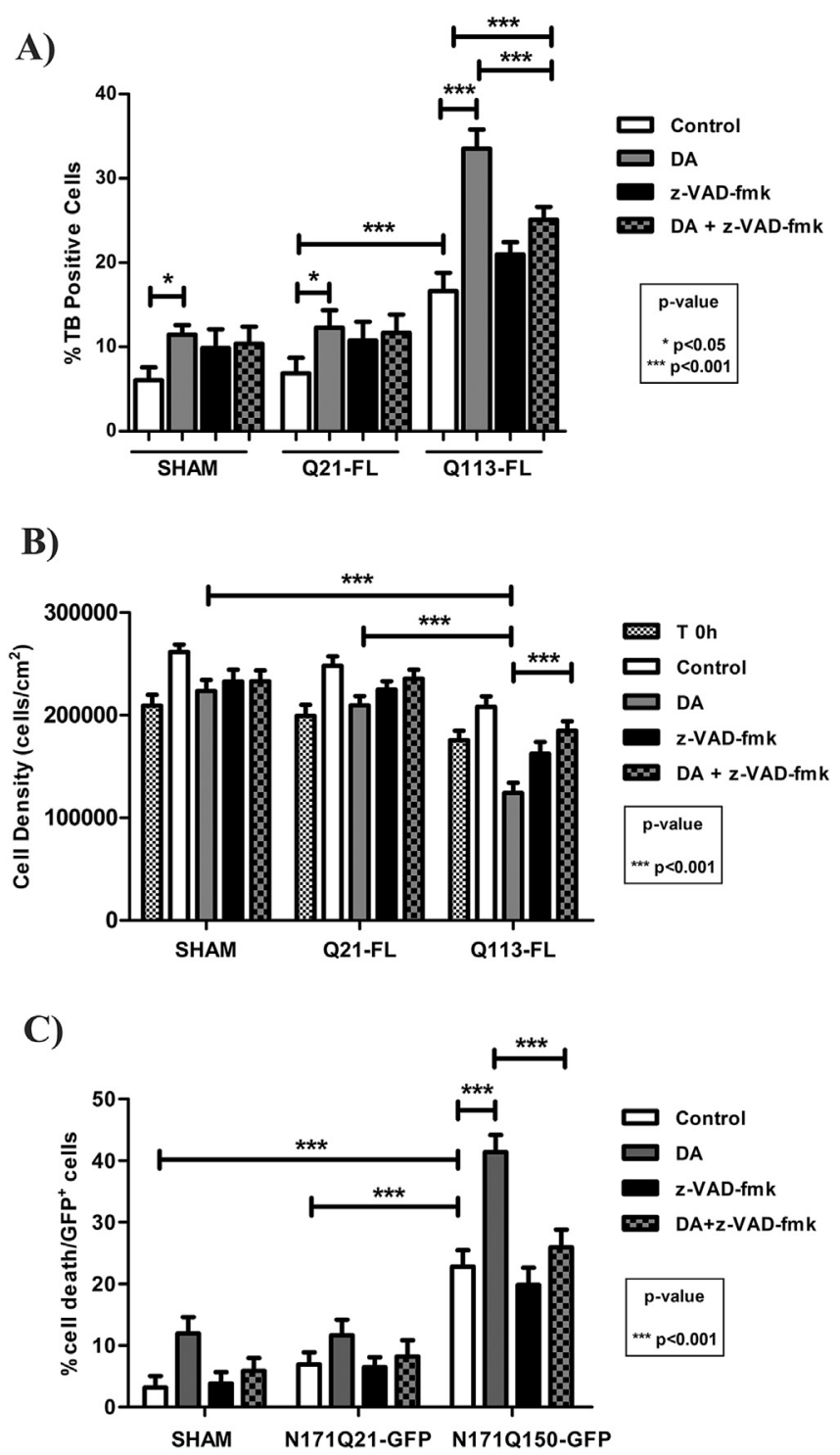

Fig. 2. Dopamine induces cell apoptosis in polyQ Htt expressing SH-SY5Y neuroblastoma cells. SH-SY5Y cells adherent on sterile plastic dishes, were transfected with pcDNA3 (SHAM), Q21-FL, Q113-FL, then incubated with $100 \mu \mathrm{M}$ DA in the presence or absence of the pancaspase inhibitor z-VAD-fmk for $24 \mathrm{~h}$. At the end of the treatment, cell necrosis was assessed by trypan blue staining (A) and cell density in the cultures was determined by cell counting (B). (C) SH-SY5Y cells were plated on coverslip, transfected with pEGFP-C2 (SHAM-GFP), N171Q21-GFP, N171Q150-GFP, then incubated with $100 \mu \mathrm{M}$ DA in the presence or absence of the pancaspase inhibitor z-VAD-fmk for $24 \mathrm{~h}$. At the end of the treatment, cell death (necrosis) was assessed by PI staining in not-fixed cells. Only transfected cells (GFP positive) were considered. Data in this figure arise from four separate replicates and are presented as average \pm S.D. Statistical analysis demonstrates that the deleterious effect of DA and the protective effect of zVAD-fmk effect on cell culture growth, necrosis and cell survival in $\mathrm{mHtt}$ expressing cultures is significant.

data indicate that $\mathrm{Htt}$ is translocated in the autophagy-lysosomal compartments. Next, we investigated whether and how DA could interfere with the autophagy flux in the cells expressing the mHtt. To this end, the cells expressing either the wild-type (Q21-FL) or the mutant (Q113-FL) Htt and exposed (or not) to DA were stained for LC3 and LAMP1 (the latter is a marker of endosomes and lysosomes). The images in Fig. $3 \mathrm{C}$ prove that upon exposure to DA the co-localization of these two markers (indicative of autolysosome formation) is drastically reduced, along with the single staining of 
A)

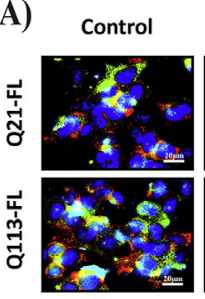

B)

PstA

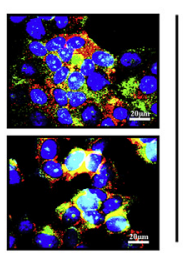

B) control

PstA

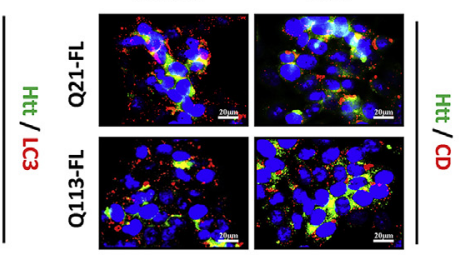

C)

SHAM

Q21-FL

Q113-FL
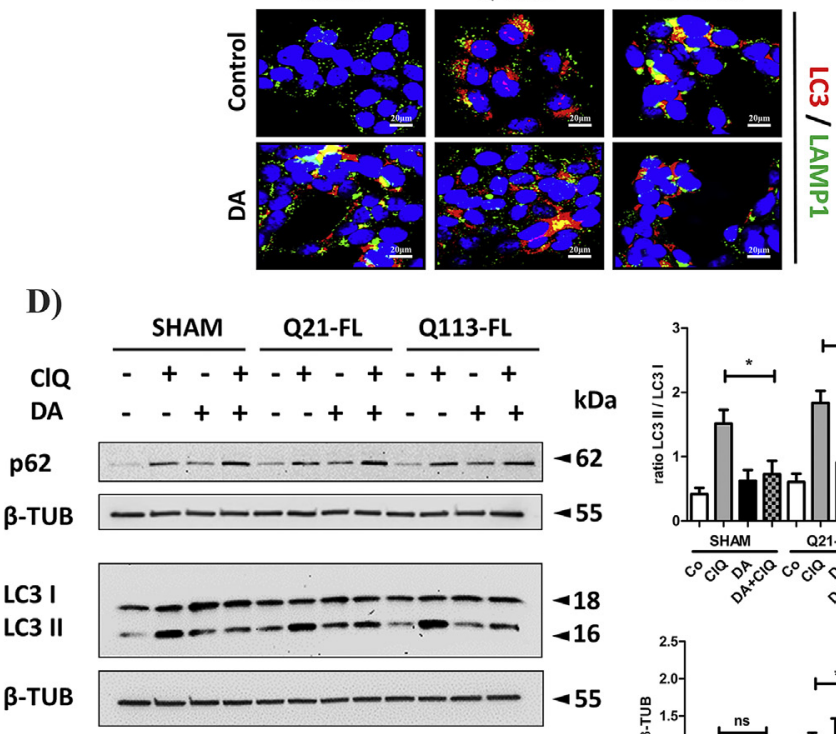

E)
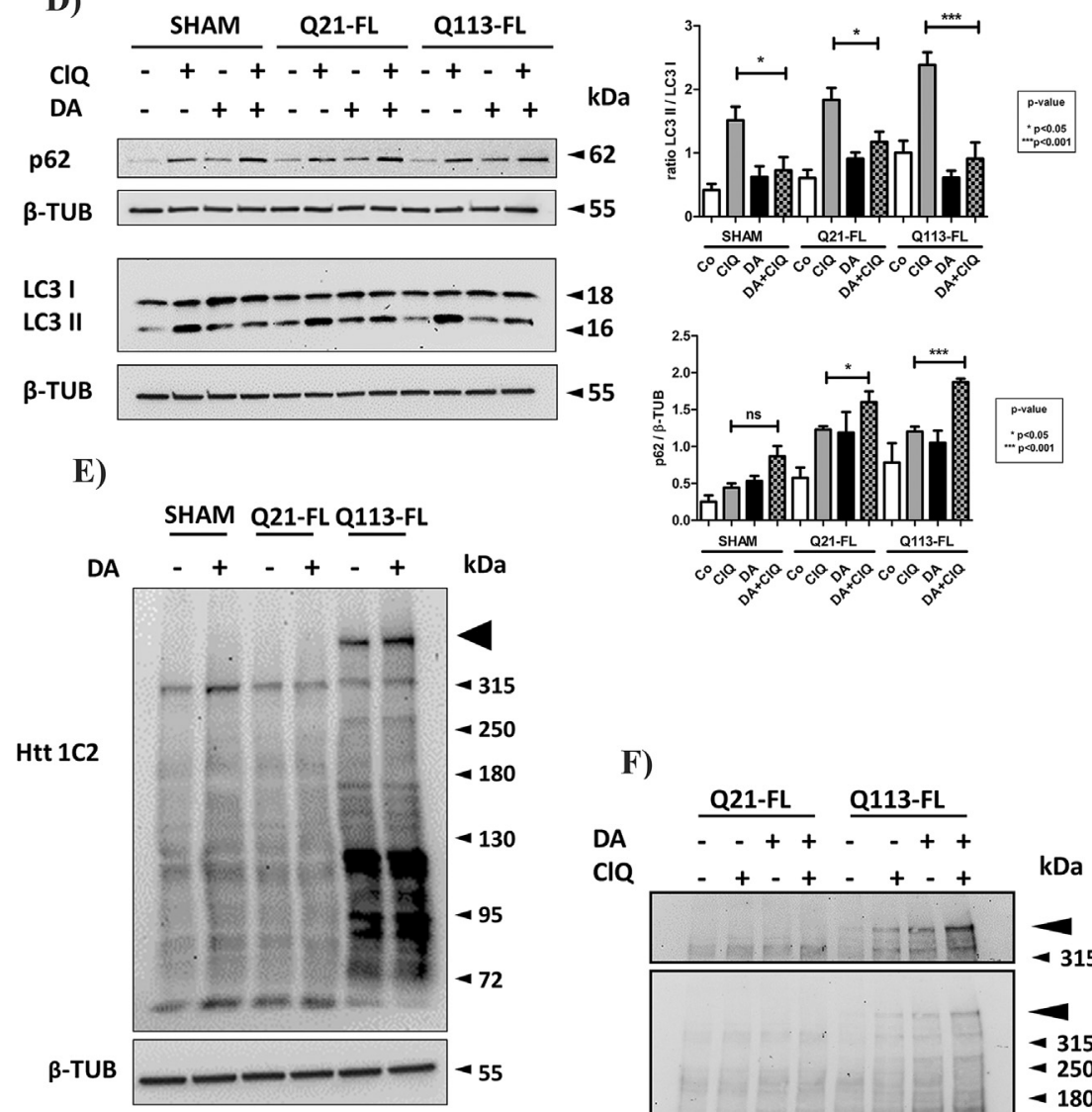

F)

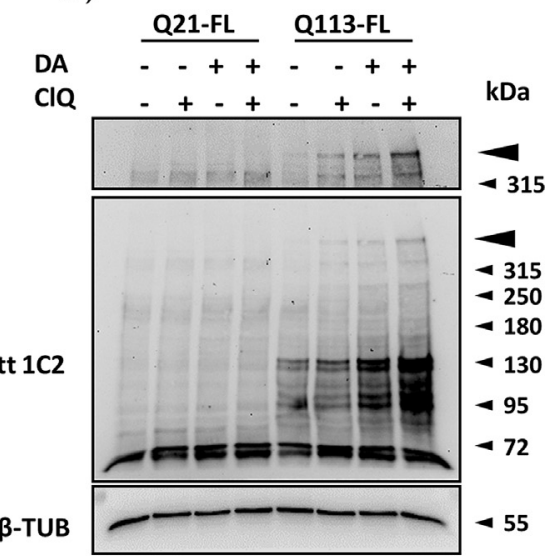

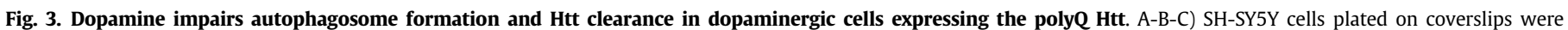

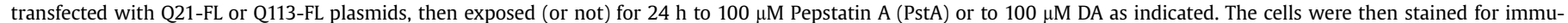

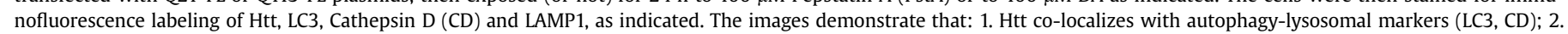

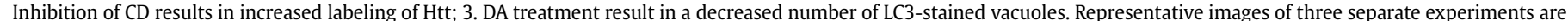

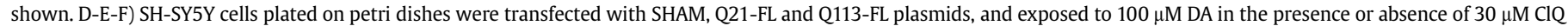

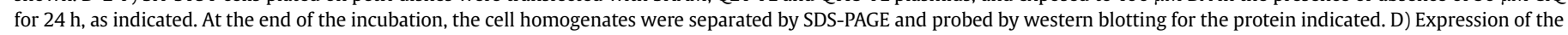

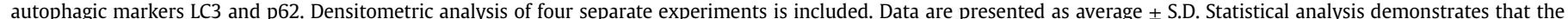

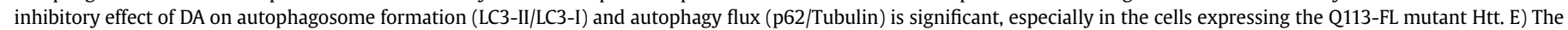

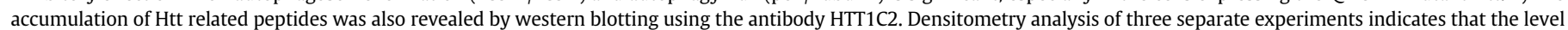

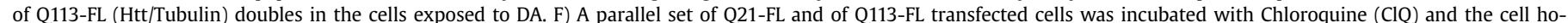

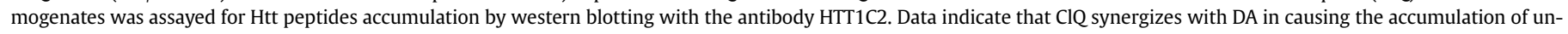
degraded mHtt (a darker exposure of the blot is shown in the upper part of the panel). 

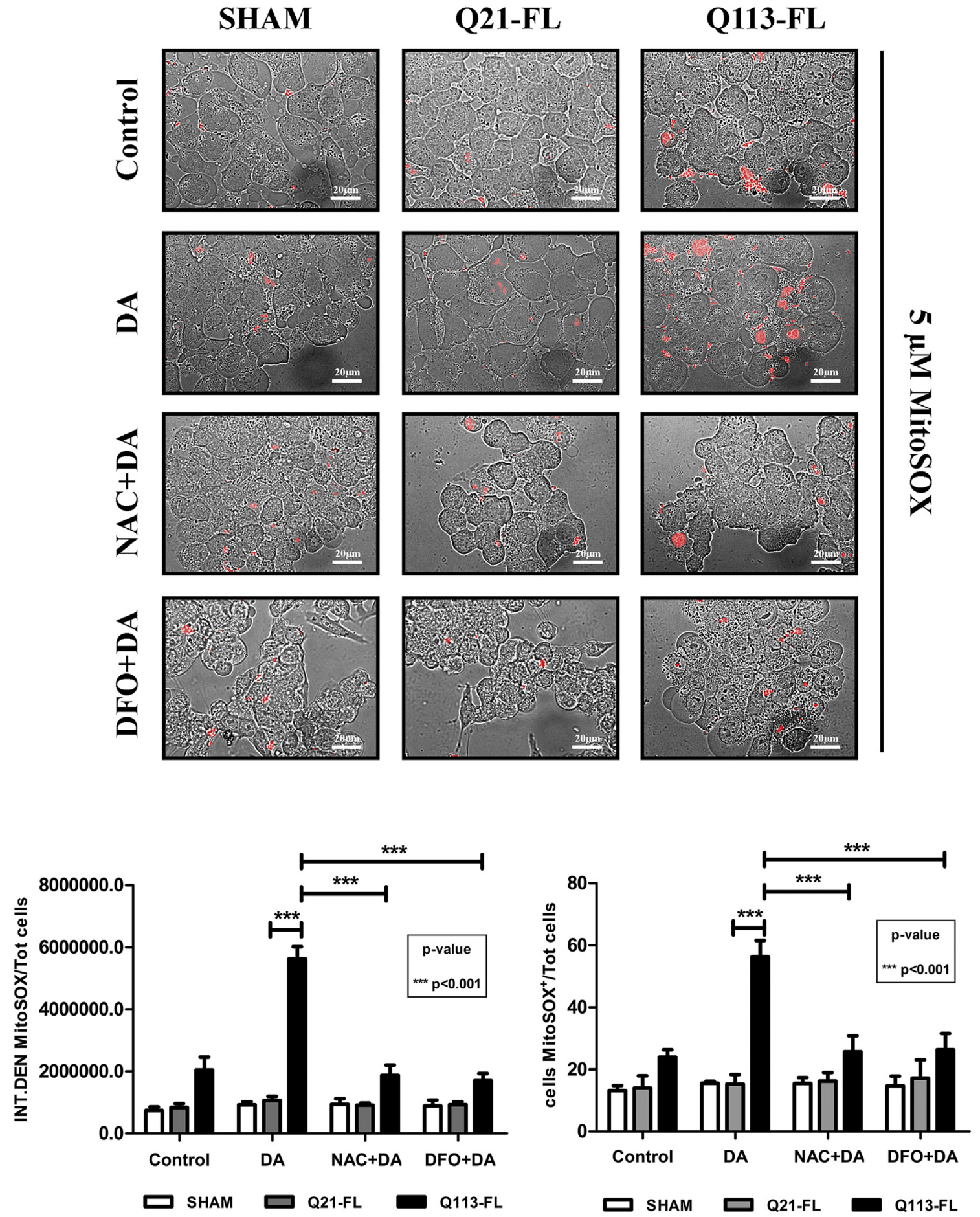

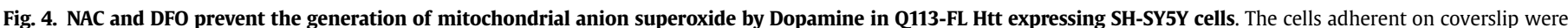

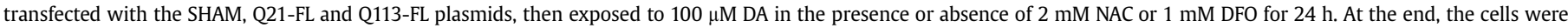

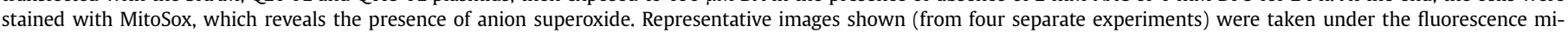

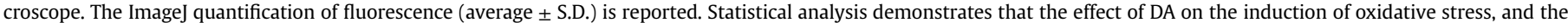
protective effect of NAC and of DFO, in Q113-FL transfected cells are significant.

LC3 (marker of autophagosomes), in the cells expressing the mHtt. To better assess the potential inhibitory effect of DA on the autophagy process, we analyzed the rate of conversion of LC3-I (localized in the cytoplasm) into LC3-II (the lipidated isoform that localizes on the autophagosomal membranes). To follow the net production of autophagosome in the various experimental conditions, in parallel samples we included Chloroquine (ClQ) that prevents the degradation of autophagosomes, thus allowing the accumulation of all the autophagosomes produced in the incubation time (Klionsky et al., 2016). Assuming the ratio LC3II/LC3I as a measure of autophagosomes (Klionsky et al., 2016), it appears that the expression of the Q113-FL induces the autophagy process, at least at the first step of autophagosome formation (compare the samples with $\mathrm{ClQ}$ in Fig. 3D). The increased production of 

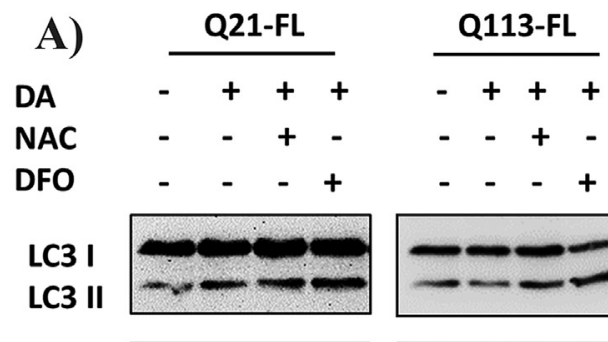

$\beta$-TUB

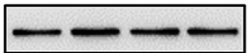$$
\text { ...+ }
$$

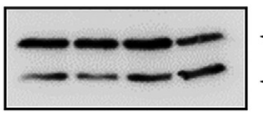

$k D a$

$-18$

$-16$

$-55$
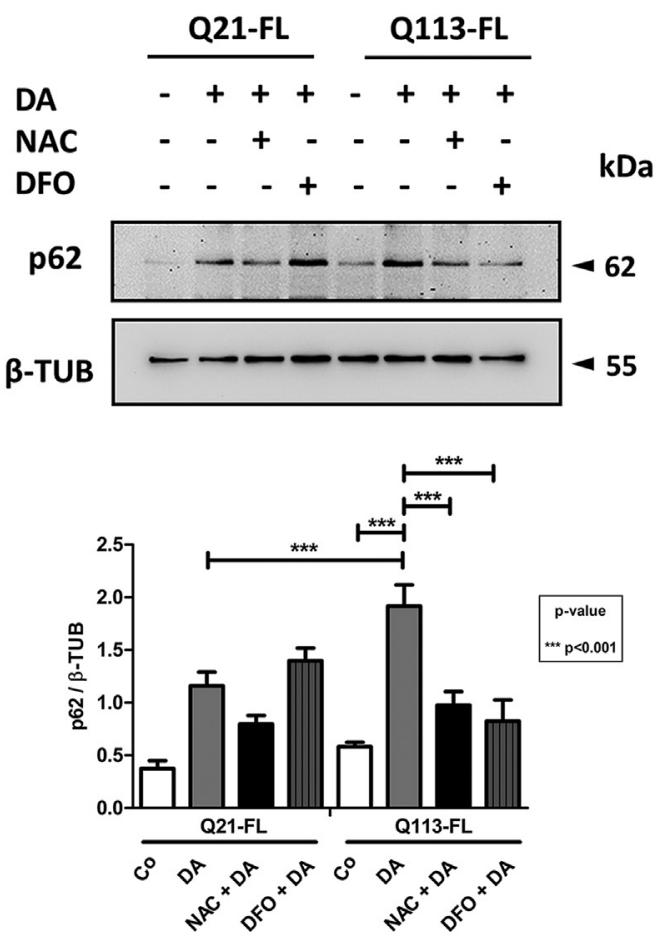

Da

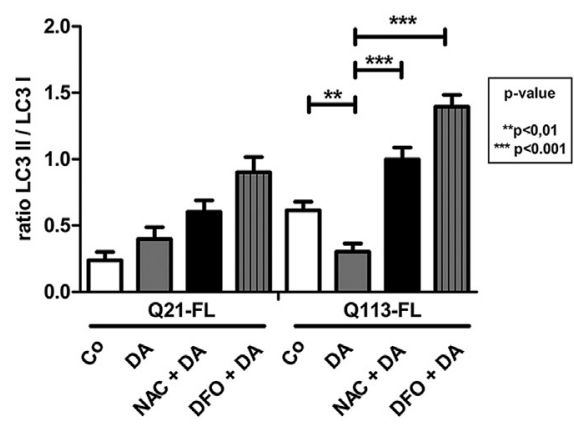

C)

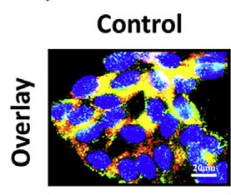

B)

Q21-FL Q113-FL

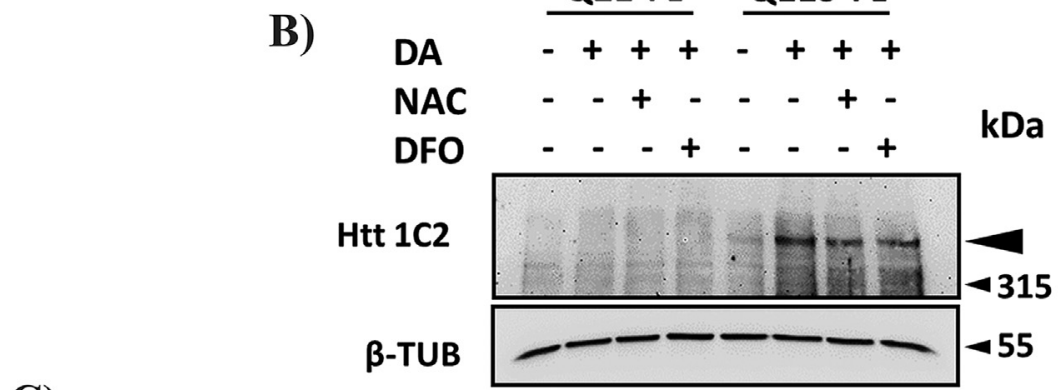

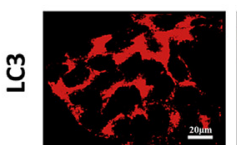
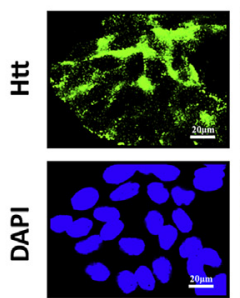
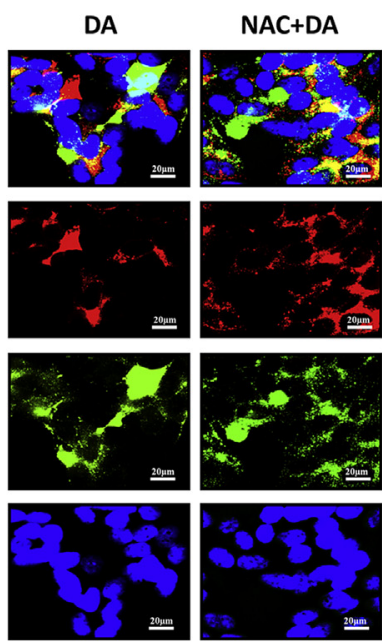
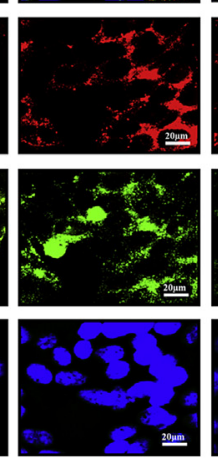

DFO+DA
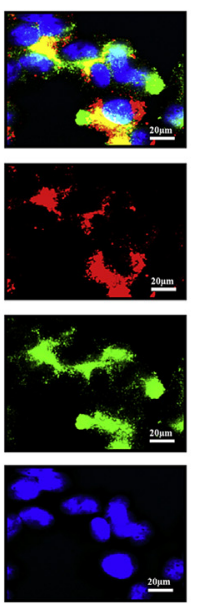

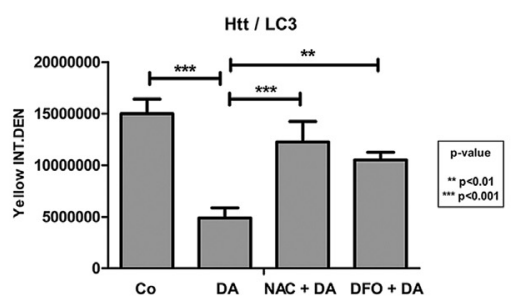

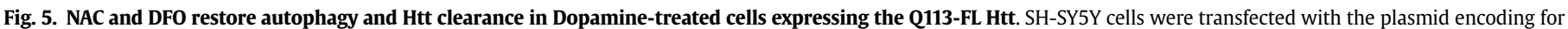

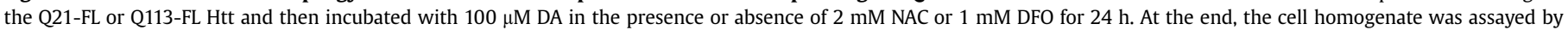

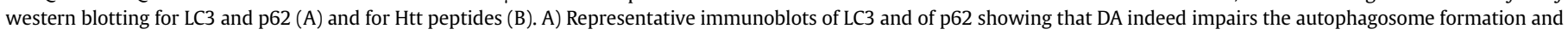

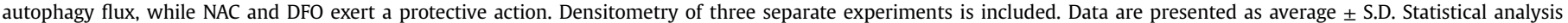

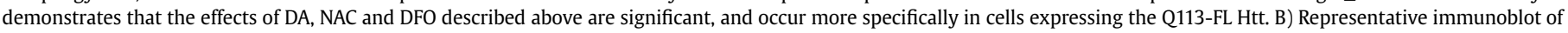

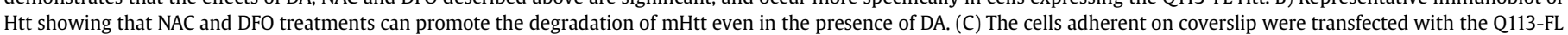

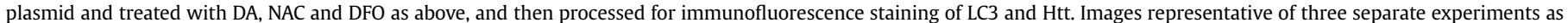

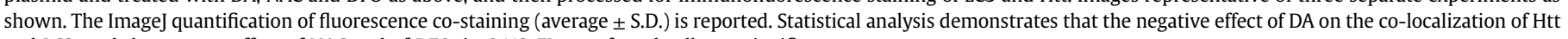
and LC3, and the counter effect of NAC and of DFO, in Q113-FL transfected cells are significant. 
A)

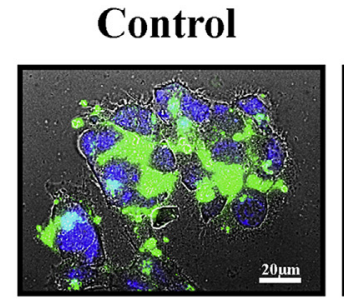

DA

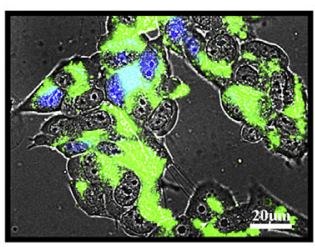

$\mathbf{N A C}+\mathbf{D A}$

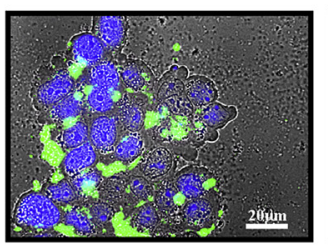

DFO+DA

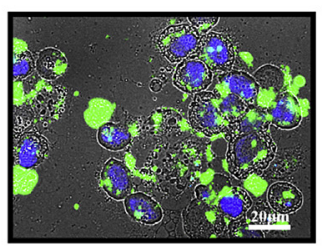

N171Q150-GFP / Cell tracker
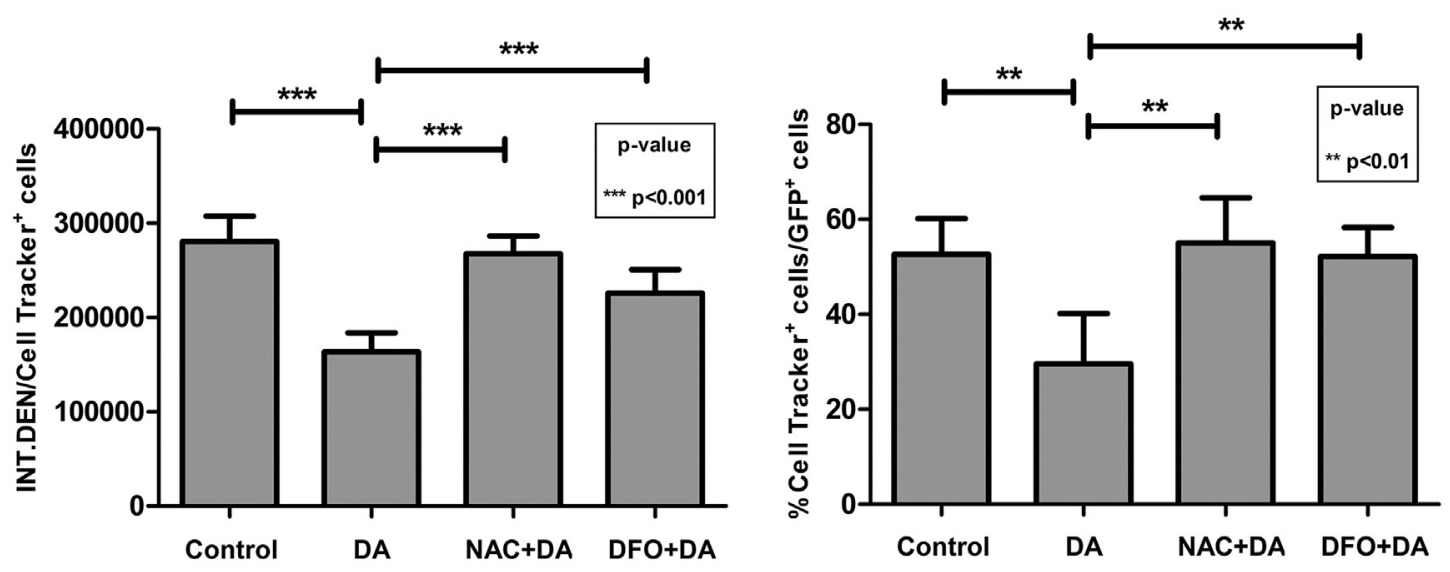

B)

Control

DA
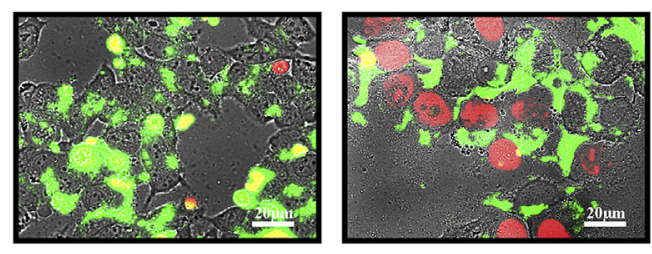

NAC+DA

DFO+DA
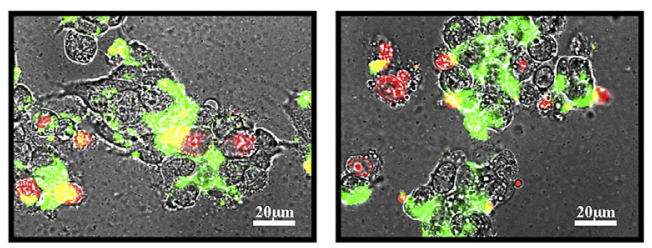

N171Q150-GFP / PI

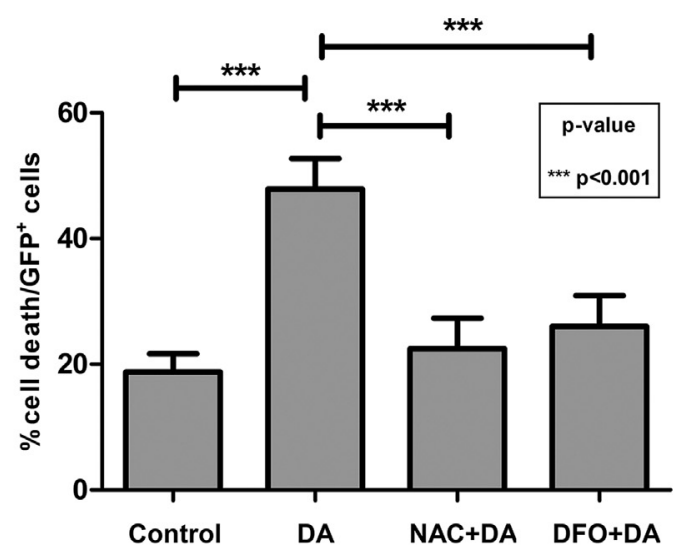

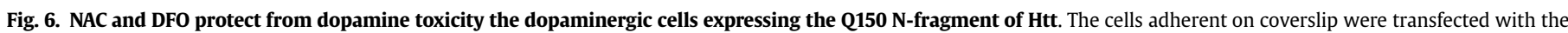

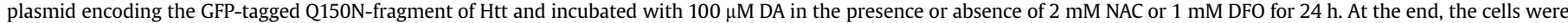

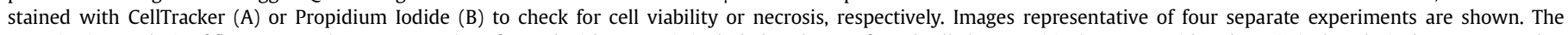

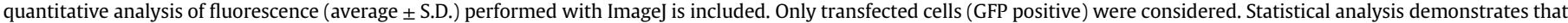
the deleterious effect of DA on cell survival, and the protective effect of NAC and of DFO, are significant. 
autophagosomes is however not observed in the cultures exposed to DA (Fig. 3D). In all conditions DA precludes the consumption of LC3II, suggesting a block of the autophagy flux. Monitoring the autophagy flux as ratio of SQSTM1/p62 degradation leads to the same conclusion (Fig. 3D). Finally, we investigated the functional consequences of DA effects on the autophagy clearance of Htt aggregates. As shown by western blotting, DA treatment led to an accumulation of the high molecular weight $\mathrm{Htt}$-related products in the cells transfected with the Q113-FL plasmid (Fig. 3E). This effect was additive to that of $\mathrm{ClQ}$, confirming that degradation of the $\mathrm{mHtt}$ occurs in acidic compartments, namely the lysosomes (Fig. 3F). These data strongly indicate that DA negatively affect the autophagy clearance of mHtt.

\subsection{Reactive oxygen species mediate the Dopamine impairment of the autophagy process}

The relationship between oxidative stress and autophagy is complex, being cell context and ROS type dependent. While low level of hydrogen peroxide has been shown to induce autophagy (Scherz-Shouval et al., 2007; Castino et al., 2010, 2011; Higgins et al., 2011; Oh et al., 2012), high level of anion superoxide may elicit the opposite effect (Janda et al., 2012, 2015). Anion superoxide is formed at mitochondrial level and can be monitored with the fluorescent dye MitoSOX (Castino et al., 2010). We first labeled the mitochondria with Rhodamine 123, which accumulates in the intermembrane space of healthy mitochondria and fluoresces in red if their membrane potential is preserved. We found that the expression of the Q113-FL mHtt per se was toxic to mitochondria, and the toxicity in these cells was exacerbated by DA (Supplementary Fig. S4). Mitochondrial function in these cultures was rescued when the cells had been pre-incubated with NAC or DFO, which are well known to prevent the formation of ROS (Papa and Rockwell, 2008; Castino et al., 2007, 2011; Zhang et al., 2009; Janda et al., 2015; Jiao et al., 2016). To confirm the involvement of anion superoxide in the toxic effect of DA, we stained the cultures with MitoSOX. The images in Fig. 4 clearly demonstrate that in the cells expressing the mutant form of Htt (Q113-FL) DA indeed stimulates the production of anion superoxide and that this could be prevented by NAC or DFO. Next we checked if DA-induced ROS are directly responsible for the impairment in autophagosome formation. To this end, we assayed the production and accumulation of LC3II and measured the degradation of p62 in the cells transfected with the Q21-FL (wild type) or the Q113-FL (mutant) $\mathrm{Htt}$ and exposed to DA in the absence or the presence of NAC or DFO. The western blotting shown in Fig. 5A demonstrates that in the cells DA indeed impairs the conversion of LC3I into LC3II (index of impaired formation of autophagosomes) and causes the accumulation of p62 (index of reduced degradation of autophagy substrates). Of note, the inhibitory effect of DA was especially evident in the cells expressing the mHtt. Remarkably, when the cells were pre-incubated with NAC or DFO the deleterious effects of DA on the autophagy process were completely abrogated (Fig. 5A). These effects reflected on the degradation of $\mathrm{mHtt}$ in that DA led to an accumulation of un-degraded Htt, while both NAC and DFO could rescue the ability to degrade this molecule (Fig. 5B and Supplementary Fig. S5B). To confirm that degradation of $\mathrm{mHtt}$ occurred via autophagy, we double stained the cells for the transgenic mHtt and for LC3. The images in Fig. 5C shows that in untreated cells mHtt and LC3 co-localize, suggesting that Q113-FL mutant Htt can be sequestered within the autophagy-lysosomal compartments and that in DA-treated cells this co-localization is less apparent and $\mathrm{mHtt}$ accumulates in the cytoplasm (consistent with data in Fig. $3 \mathrm{~A}-\mathrm{C}$ ). To be noted, the pre-incubation with either NAC or DFO counteracts the negative effects of DA on autophagy
(Fig. 5C).

\subsection{Preventing ROS generation saves the dopaminergic cells expressing $\mathrm{mHtt}$ from Dopamine toxicity}

The above data showed that DA caused toxicity in dopaminergic neuroblastoma cells expressing the $\mathrm{mHtt}$ and concomitantly induced the generation of anion superoxide and inhibited the formation of autophagosomes, which resulted in the accumulation of mHtt. We also showed that NAC and DFO could prevent the ROS generation and relief the inhibition on the autophagy system. We then checked whether the pre-treatment with NAC or DFO could save the dopaminergic cells expressing the polyQ N-terminal fragment of Htt from DA toxicity. To this end, we have transfected SH-SY5Y cells with the plasmid bearing the GFP-tagged N-fragment with Q150 and then checked for cell viability (by CellTracker staining) and necrosis (by PI staining) in non-fixed cultures. The images shown in Fig. 6 clearly demonstrate that both NAC and DFO can preserve cell viability (panel A) and limit necrosis (panel B) in the cultures expressing the polyQ fragment and exposed to DA. Quantification of viability-associated fluorescence with ImageJ software confirmed that the polyQ N-terminal fragment is per se toxic and that DA exacerbates this toxicity. However, the preincubation with NAC or DFO greatly reduces the toxicity by DA, though cannot completely avoid the intrinsic toxicity due to the expression of the polyQ fragment. The protective effect of NAC and DFO could be evidenced by counting the proportion of viable (bluestained) cells, as well as the relative intensity of the blue staining in the cells. In numbers, DA treatment caused an increase of cell death from a basal value of approximately $20 \%$ up to approximately $50 \%$, and NAC and DFO essentially prevented this increase.

\section{Discussion}

HD patients present with chorea and Parkinson-like motor symptoms, in addition to cognitive deficits and psychiatric disturbances. Dopamine, an excitotoxic neurotransmitter, is clearly involved in the altered coordination of movement in HD patients. Time-dependent changes in DA transmission parallel biphasic changes in symptomatology. In the early stage of the disease, increased DA stimulation leads to hyperkinetic movements, while in the late stage of the disease a decrease in DA availability causes hypokinesia (Chen et al., 2013; Cepeda et al., 2014). Neurodegeneration in HD is due to the expression of a mutated Htt protein with an abnormal expansion of glutamine (polyQ tract) at the N-terminus (Rubinzstein, 2002), which likely renders the neurons (particularly the MSNs) in the striatum and other brain region frail and susceptible to die upon pro-oxidant injury. Oxidative stress is a well known cause of neurodegeneration (Janda et al., 2012). The continuous generation of ROS within the cells may have various deleterious effects, including the permeabilization of lysosomal and mitochondrial membranes with ensuing apoptosis (Castino et al., 2007; Papa and Rockwell, 2008), the altered folding of proteins with consequent formation of protein macro-aggregates (Castino et al., 2008a; Nakamura et al., 2012; Halloran et al., 2013), and the inhibition of autophagy process (Janda et al., 2015). Effective autophagy allows dopaminergic neuronal cells to face with oxidative stress (Castino et al., 2008a). Neuronal cells expressing mutated aggregate-prone proteins are clearly more susceptible to such damage caused by oxidative stress (Janda et al., 2015; Isidoro et al., 2009). In particular, the impairment of autophagy may have dramatic effects in diseased neurons, since this pathway is devoted to the clearance of unfolded protein aggregates and of leaky mitochondria (Castino et al., 2008b; Cherra et al., 2010). Yet, the sustained hyper-induction of autophagy is deleterious as well to 
neurons (Cherra et al., 2010), especially if the neurons are already subjected to an endogenous stress that maintains autophagy at high level. The double-hit hypothesis well illustrates this case (Castino et al., 2005b). It has been shown that neurons expressing a truncated aggregate prone mutant of Vasopressin can survive thanks to the up-regulation of autophagy that continuously clear the aggregates (Castino et al., 2005a). Yet, these cells precipitate into apoptosis when they are stimulated with an excitotoxic stimulus (e.g., DA) that increases further autophagy (Castino et al., 2005b). In HD neurons autophagy appears to be insufficient, since drugs that stimulate autophagy elicit beneficial effects in clearing Htt and thus preventing cell death 'in vitro' (Bjørkøy et al., 2005; Qin et al., 2003), and in relieving the symptoms in HD animal models (Sarkar and Rubinsztein, 2008; Fusco et al., 2012). Once delivered to lysosomes, $\mathrm{Htt}$ is proteolytically processed by lysosomal cathepsins B and D (Qin et al., 2003). Important to note, Htt itself promotes the autophagy sequestration and clearance of aggregates by interacting with p62/SQSTM1 and with ULK1 (Rui et al., 2015). Conversely, mHtt negatively affects the p62-mediated sequestration of autophagy substrates (Martinez-Vicente et al., 2010). Thus, it is reasonable to assume that neuronal cell death in HD neurons is a consequence of an impairment of the autophagy flux. Here we show that DA stimulation can indeed cause an impairment of autophagy and thereafter precipitate cell death in dopaminergic neuroblastoma cells expressing the mutant $\mathrm{Htt}$ at high level. This is at variance of what we have previously observed in dopaminergic cells expressing the truncated mutant Vasopressin (Castino et al., 2005b), indicating that the outcome of DA treatment is cellcontext, likely depending on the type and subcellular localization of the mutated protein. In fact, mutated Vasopressin forms aggregates within the endoplasmic reticulum and induces a raise of basal autophagy (Castino et al., 2005a), whereas Htt locates in the cytoplasm. Also, different types of ROS may elicit different effects depending on the genetic background of the cell. Oxidative stress could be an effective cause of autophagy impairment. We have previously shown that mitochondrial ROS (particularly anion superoxide) inhibit the conversion of LC3-I into LC3-II, thus impairing autophagosome formation and degradation, despite the concurrent activation of several pro-autophagic signaling pathways (Janda et al., 2015). Similarly, a block of the autophagic flux along with up-regulation of ATG proteins has been reported in neurons expressing mutant Htt (Heng et al., 2010). It was already reported that elevated NADPH oxidase activity increases the production of ROS and favors the onset of cell death in Htt expressing neurons (Valencia et al., 2013). Consistently, we found that DA induces the production of anion superoxide (associated with dysfunctional mitochondria) that eventually cause the impairment of autophagosome formation. In fact, in DA-treated cells expressing the $\mathrm{mHtt}$ or the polyQ N-fragment, NAC and DFO could prevent the generation of such ROS and allowed the induction of protective autophagy. DFO was already shown to protect dopaminergic neuroblastoma cells from oxidative stress (Castino et al., 2007, 2011), as well as striatal neuron from dopaminergic toxicity (Haleagrahara et al., 2013). Similarly, NAC has been proven to prevent mitochondrial dysfunction in 'in vitro' HD models (Sandhir et al., 2012) and to delay the onset of motor deficits in HD animal models (Wright et al., 2015). In conclusion, the present study provides a mechanistic explanation for the dopaminergic cell toxicity observed in HD patients, and gives further support to the potential of anti-oxidant therapeutics to arrest the progression of the disease (Melone et al., 2005).

\section{Acknowledgements}

C.V. is a PhD student supported by the Ministry of Education,
Universities and Research (MIUR; Italy). Researches in the laboratories of M.A.B.M. and C.I. are supported by a grant from MIUR under PRIN contract \#20109MXHMR_004.

\section{Appendix A. Supplementary data}

Supplementary data related to this article can be found at http:// dx.doi.org/10.1016/j.neuint.2016.11.003.

\section{References}

Bäckman, L., Farde, L., 2001. Dopamine and cognitive functioning: brain imaging findings in Huntington's disease and normal aging. Scand. J. Psychol. 42 (3), 287-296 (Review).

Bjørkøy, G., Lamark, T., Brech, A., Outzen, H., Perander, M., Overvatn, A Stenmark, H., Johansen, T., 2005. p62/SQSTM1 forms protein aggregates degraded by autophagy and has a protective effect on huntingtin-induced cel death. J. Cell Biol. 171 (4), 603-614.

Cagnin, M., Ozzano, M., Bellio, N., Fiorentino, I., Follo, C., Isidoro, C., 2012. Dopamine induces apoptosis in APPswe-expressing Neuro2A cells following Pepstatinsensitive proteolysis of APP in acid compartments. Brain Res. 1471, 102-117. http://dx.doi.org/10.1016/j.brainres.2012.06.025.

Castino, R., Davies, J., Beaucourt, S., Isidoro, C., Murphy, D., 2005a. Autophagy is a prosurvival mechanism in cells expressing an autosomal dominant familia neurohypophyseal diabetes insipidus mutant vasopressin transgene. FASEB J. 19 (8), 1021-1023.

Castino, R., Isidoro, C., Murphy, D., 2005b. Autophagy-dependent cell survival and cell death in an autosomal dominant familial neurohypophyseal diabetes insipidus in vitro model. FASEB J. 19 (8), 1024-1026.

Castino, R., Bellio, N., Nicotra, G., Follo, C., Trincheri, N.F., Isidoro, C., 2007. Cathepsin D-Bax death pathway in oxidative stressed neuroblastoma cells. Free Radic. Biol. Med. 42 (9), 1305-1316.

Castino, R., Lazzeri, G., Lenzi, P., Bellio, N., Follo, C., Ferrucci, M., Fornai, F., Isidoro, C., 2008a. Suppression of autophagy precipitates neuronal cell death following low doses of methamphetamine. J. Neurochem. 106 (3), 1426-1439. http:/ dx.doi.org/10.1111/j.1471-4159.2008.05488.

Castino, R., Thepparit, C., Bellio, N., Murphy, D., Isidoro, C., 2008b. Akt induces apoptosis in neuroblastoma cells expressing a C98X vasopressin mutant following autophagy suppression. J. Neuroendocrinol. 20 (10), 1165-1175. http://dx.doi.org/10.1111/j.1365-2826.2008.01769.

Castino, R., Bellio, N., Follo, C., Murphy, D., Isidoro, C., 2010. Inhibition of PI3k class III-dependent autophagy prevents apoptosis and necrosis by oxidative stress in dopaminergic neuroblastoma cells. Toxicol. Sci. 117 (1), 152-162. http:// dx.doi.org/10.1093/toxsci/kfq170.

Castino, R., Fiorentino, I., Cagnin, M., Giovia, A., Isidoro, C., 2011. Chelation of lysosomal iron protects dopaminergic SH-SY5Y neuroblastoma cells from hydrogen peroxide toxicity by precluding autophagy and Akt dephosphorylation. Toxicol. Sci. 123 (2), 523-541. http://dx.doi.org/10.1093/toxsci/kfr179.

Cepeda, C., Murphy, K.P., Parent, M., Levine, M.S., 2014. The role of dopamine in Huntington's disease. Prog. Brain Res. 211, 235-254. http://dx.doi.org/10.1016/ B978-0-444-63425-2.00010-6 (Review)

Chen, J.Y., Wang, E.A., Cepeda, C., Levine, M.S., 2013. Dopamine imbalance in Huntington's disease: a mechanism for the lack of behavioral flexibility. Front Neurosci. 7, 114. http://dx.doi.org/10.3389/fnins.2013.00114.

Cherra 3rd, S.J., Dagda, R.K., Chu, C.T., 2010. Review: autophagy and neurodegeneration: survival at a cost? Neuropathol. Appl. Neurobiol. 36 (2), 125-132. http://dx.doi.org/10.1111/j.1365-2990.2010.01062 (Review).

DiFiglia, M., Sapp, E., Chase, K.O., Davies, S.W., Bates, G.P., Vonsattel, J.P., Aronin, N. 1997. Aggregation of huntingtin in neuronal intranuclear inclusions and dystrophic neurites in brain. Science 277 (5334), 1990-1993.

Ekkapongpisit, M., Giovia, A., Nicotra, G., Ozzano, M., Caputo, G., Isidoro, C., 2012 Labeling and exocytosis of secretory compartments in RBL mastocytes by polystyrene and mesoporous silica nanoparticles. Int. J. Nanomedicine. 7 1829-1840. http://dx.doi.org/10.2147/IJN.S29034.

Erdmann, S., Ricken, A., Merkwitz, C., Struman, I., Castino, R., Hummitzsch, K. Gaunitz, F., Isidoro, C., Martial, J., Spanel-Borowski, K., 2007. The expression of prolactin and its cathepsin D-mediated cleavage in the bovine corpus luteum vary with the estrous cycle. Am. J. Physiol. Endocrinol. Metab. 293 (5), E1365-E1377.

Follo, C., Ozzano, M., Mugoni, V., Castino, R., Santoro, M., Isidoro, C., 2011. Knockdown of cathepsin D affects the retinal pigment epithelium, impairs swimbladder ontogenesis and causes premature death in zebrafish. PLoS One. 6 (7), e21908. http://dx.doi.org/10.1371/journal.pone.0021908.

Fusco, F.R., Anzilotti, S., Giampà, C., Dato, C., Laurenti, D., Leuti, A., Colucci D'Amato, L., Perrone, L., Bernardi, G., Melone, M.A., 2012. Changes in the expression of extracellular regulated kinase (ERK 1/2) in the R6/2 mouse model of Huntington's disease after phosphodiesterase IV inhibition. Neurobiol. Dis. 46 (1), 225-233. http://dx.doi.org/10.1016/j.nbd.2012.01.011.

Garrett, M.C., Soares-da-Silva, P., 1992. Increased cerebrospinal fluid dopamine and 3,4-dihydroxyphenylacetic acid levels in Huntington's disease: evidence for an overactive dopaminergic brain transmission. J. Neurochem. 58 (1), 101-106. 
Haleagrahara, N., Siew, C.J., Ponnusamy, K., 2013. Effect of quercetin and desferrioxamine on 6-hydroxydopamine (6-OHDA) induced neurotoxicity in striatum of rats. J. Toxicol. Sci. 38 (1), 25-33.

Halloran, M., Parakh, S., Atkin, J.D., 2013. The role of s-nitrosylation and s-glutathionylation of protein disulphide isomerase in protein misfolding and neurodegeneration. Int. J. Cell Biol. 2013, 797914. http://dx.doi.org/10.1155/2013/ 797914 (Review).

Heiseke, A., Aguib, Y., Riemer, C., Baier, M., Schätzl, H.M., 2009. Lithium induces clearance of protease resistant prion protein in prion-infected cells by induction of autophagy. J. Neurochem. 109 (1), 25-34. http://dx.doi.org/10.1111/j.1471 4159.2009.05906.

Heng, M.Y., Duong, D.K., Albin, R.L., Tallaksen-Greene, S.J., Hunter, J.M., Lesort, M.J., Osmand, A., Paulson, H.L., Detloff, P.J., 2010. Early autophagic response in a novel knock-in model of Huntington disease. Hum. Mol. Genet. 19 (19), 3702-3720. http://dx.doi.org/10.1093/hmg/ddq285.

Higgins, G.C., Devenish, R.J. Beart, P.M. Nagley, P., 2011. Autophagic activity in cortical neurons under acute oxidative stress directly contributes to cell death. Cell Mol. Life Sci. 68 (22), 3725-3740. http://dx.doi.org/10.1007/s00018-0110667-9.

Isidoro, C., Biagioni, F., Giorgi, F.S., Fulceri, F., Paparelli, A., Fornai, F., 2009. The role of autophagy on the survival of dopamine neurons. Curr. Top. Med. Chem. 9 (10), 869-879 (Review).

Jakel, R.J., Maragos, W.F., 2000. Neuronal cell death in Huntington's disease: a potential role for dopamine. Trends Neurosci. 23 (6), 239-245 (Review).

Janda, E., Isidoro, C., Carresi, C., Mollace, V., 2012. Defective autophagy in Parkinson's disease: role of oxidative stress. Mol. Neurobiol. 46 (3), 639-661. http:| dx.doi.org/10.1007/s12035-012-8318-1 (Review).

Janda, E., Lascala, A., Carresi, C., Parafati, M., Aprigliano, S., Russo, V., Savoia, C., Ziviani, E., Musolino, V., Morani, F., Isidoro, C., Mollace, V., 2015. Parkinsonian toxin-induced oxidative stress inhibits basal autophagy in astrocytes via NQO2 quinone oxidoreductase 2: implications for neuroprotection. Autophagy 11 (7), 1063-1080. http://dx.doi.org/10.1080/15548627.2015.1058683.

Jiao, Y., Ma, S., Wang, Y., Li, J., Shan, L., Liu, Q., Liu, Y., Song, Q., Yu, F., Yu, H., Liu, H. Huang, L., Chen, J., 2016. N-acetyl cysteine depletes reactive oxygen species and prevents dental monomer-induced intrinsic mitochondrial apoptosis in vitro in human dental pulp cells. PLoS One 11 (1), e0147858. http://dx.doi.org/10.1371/ journal.pone.0147858.

Kish, S.J., Shannak, K., Hornykiewicz, O., 1987. Elevated serotonin and reduced dopamine in subregionally divided Huntington's disease striatum. Ann. Neurol. 22 (3), 386-389.

Klionsky, D.J., Abdelmohsen, K., Abe, A., et al., 2016. Guidelines for the use and interpretation of assays for monitoring autophagy (3rd edition). Autophagy 12 (1), 1-222. http://dx.doi.org/10.1080/15548627.2015.1100356.

Martinez-Vicente, M., Talloczy, Z., Wong, E., Tang, G., Koga, H., Kaushik, S., de Vries, R., Arias, E., Harris, S., Sulzer, D., Cuervo, A.M., 2010. Cargo recognition failure is responsible for inefficient autophagy in Huntington's disease. Nat. Neurosci. 13 (5), 567-576. http://dx.doi.org/10.1038/nn.2528.

Melone, M.A., Jori, F.P., Peluso, G., 2005. Huntington's disease: new frontiers for molecular and cell therapy. Curr. Drug Targets. 6 (1), 43-56 (Review).

Nakamura, T., Cho, D.H., Lipton, S.A., 2012. Redox regulation of protein misfolding, mitochondrial dysfunction, synaptic damage, and cell death in neurodegenerative diseases. Exp. Neurol. 238 (1), 12-21. http://dx.doi.org/10.1016/ j.expneurol.2012.06.032. Epub 2012 Jul 5. Review.

Oh, J.M., Choi, E.K., Carp, R.I., Kim, Y.S., 2012. Oxidative stress impairs autophagic flux in prion protein-deficient hippocampal cells. Autophagy 8 (10), 1448-1461. http://dx.doi.org/10.4161/auto.21164.

Papa, L., Rockwell, P., 2008. Persistent mitochondrial dysfunction and oxidative stress hinder neuronal cell recovery from reversible proteasome inhibition Apoptosis 13 (4), 588-599. http://dx.doi.org/10.1007/s10495-008-0182-0.

Persichetti, F., Trettel, F., Huang, C.C., Fraefel, C., Timmers, H.T., Gusella, J.F. MacDonald, M.E., 1999. Mutant huntingtin forms in vivo complexes with distinct context-dependent conformations of the polyglutamine segment. Neurobiol. Dis. 6 (5), 364-375.

Petersén, A., Hansson, O., Puschban, Z., Sapp, E., Romero, N., Castilho, R.F., Sulzer, D. Rice, M., DiFiglia, M., Przedborski, S., Brundin, P., 2001a. Mice transgenic for exon 1 of the Huntington's disease gene display reduced striatal sensitivity to neurotoxicity induced by dopamine and 6-hydroxydopamine. Eur. J. Neurosci. 14 (9), 1425-1435.

Petersén, A., Larsen, K.E., Behr, G.G., Romero, N., Przedborski, S., Brundin, P. Sulzer, D., 2001b. Expanded CAG repeats in exon 1 of the Huntington's disease gene stimulate dopamine-mediated striatal neuron autophagy and degeneration. Hum. Mol. Genet. 10 (12), 1243-1254.

Qin, Z.H., Wang, Y., Kegel, K.B., Kazantsev, A., Apostol, B.L., Thompson, L.M., Yoder, J., Aronin, N., DiFiglia, M., 2003. Autophagy regulates the processing of amino terminal huntingtin fragments. Hum. Mol. Genet. 12 (24), 3231-3244.

Ratovitski, T., Nakamura, M., D'Ambola, J., Chighladze, E., Liang, Y., Wang, W., Graham, R. Hayden, M.R., Borchelt, D.R., Hirschhorn, R.R., Ross, C.A. 2007. Nterminal proteolysis of full-length mutant huntingtin in an inducible PC12 cell model of Huntington's disease. Cell Cycle 6 (23), 2970-2981.

Ratovitski, T., Gucek, M., Jiang, H., Chighladze, E., Waldron, E., D'Ambola, J., Hou, Z., Liang, Y., Poirier, M.A., Hirschhorn, R.R., Graham, R., Hayden, M.R., Cole, R.N., Ross, C.A., 2009. Mutant huntingtin N-terminal fragments of specific size mediate aggregation and toxicity in neuronal cells. J. Biol. Chem. 284 (16), 10855-10867. http://dx.doi.org/10.1074/jbc.M804813200.

Ravikumar, B., Vacher, C., Berger, Z., Davies, J.E., Luo, S., Oroz, L.G., Scaravilli, F., Easton, D.F., Duden, R., O'Kane, C.J., Rubinsztein, D.C., 2004. Inhibition of mTOR induces autophagy and reduces toxicity of polyglutamine expansions in fly and mouse models of Huntington disease. Nat. Genet. 36 (6), 585-595.

Roscic, A., Baldo, B., Crochemore, C., Marcellin, D., Paganetti, P., 2011. Induction of autophagy with catalytic mTOR inhibitors reduces huntingtin aggregates in a neuronal cell model. J. Neurochem. 119 (2), 398-407. http://dx.doi.org/10.1111/ j.1471-4159.2011.07435.

Rossetti, G., Magistrato, A., Pastore, A., Persichetti, F., Carloni, P., 2008. Structural properties of polyglutamine aggregates investigated via molecular dynamics simulations. J. Phys. Chem. B 112 (51), 16843-16850. http://dx.doi.org/10.1021/ jp806548p.

Rubinsztein, D.C., 2002. Lessons from animal models of Huntington's disease. Trends Genet. 18 (4), 202-209 (Review).

Rubinsztein, D.C., 2006. The roles of intracellular protein-degradation pathways in neurodegeneration. Nature 443 (7113), 780-786 (Review).

Rui, Y.N., Xu, Z., Patel, B., Chen, Z., Chen, D., Tito, A., David, G., Sun, Y., Stimming, E.F., Bellen, H.J., Cuervo, A.M., Zhang, S., 2015. Huntingtin functions as a scaffold for selective macroautophagy. Nat. Cell Biol. 17 (3), 262-275. http://dx.doi.org/ 10.1038/ncb3101.

Sandhir, R., Sood, A., Mehrotra, A., Kamboj, S.S., 2012. N-Acetylcysteine reverses mitochondrial dysfunctions and behavioral abnormalities in 3-nitropropionic acid-induced Huntington's disease. Neurodegener. Dis. 9 (3), 145-157. http:// dx.doi.org/10.1159/000334273.

Sarkar, S., Perlstein, E.O., Imarisio, S., Pineau, S., Cordenier, A., Maglathlin, R.L., Webster, J.A., Lewis, T.A., O'Kane, C.J., Schreiber, S.L., Rubinsztein, D.C., 2007. Small molecules enhance autophagy and reduce toxicity in Huntington's disease models. Nat. Chem. Biol. 3 (6), 331-338.

Sarkar, S., Krishna, G., Imarisio, S., Saiki, S., O'Kane, C.J., Rubinsztein, D.C., 2008. A rational mechanism for combination treatment of Huntington's disease using lithium and rapamycin. Hum. Mol. Genet. 17 (2), 170-178.

Sarkar, S., Rubinsztein, D.C., 2008. Huntington's disease: degradation of mutant huntingtin by autophagy. FEBS J. 275 (17), 4263-4270. http://dx.doi.org/ $10.1111 /$ j.1742-4658.2008.06562 (Review).

Scherz-Shouval, R. Shvets, E., Elazar, Z., 2007. Oxidation as a post-translational modification that regulates autophagy. Autophagy 3 (4), 371-373.

Soto, C., 2003. Unfolding the role of protein misfolding in neurodegenerative diseases. Nat. Rev. Neurosci. 4 (1), 49-60 (Review).

Valencia, A., Sapp, E., Kimm, J.S., McClory, H., Reeves, P.B., Alexander, J., Ansong, K.A., Masso, N., Frosch, M.P., Kegel, K.B., Li, X., DiFiglia, M., 2013. Elevated NADPH oxidase activity contributes to oxidative stress and cell death in Huntington's disease. Hum. Mol. Genet. 22 (6), 1112-1131. http://dx.doi.org/10.1093/hmg/ dds516.

Vidoni, C., Follo, C., Savino, M., Melone, M.A., Isidoro, C., 2016. The role of cathepsin $\mathrm{D}$ in the pathogenesis of human neurodegenerative disorders. Med. Res. Rev. 36 (5), 845-870. http://dx.doi.org/10.1002/med.21394 (Review).

Vonsattel, J.P., Myers, R.H., Stevens, T.J., Ferrante, R.J., Bird, E.D., Richardson Jr., E.P., 1985. Neuropathological classification of Huntington's disease. J. Neuropathol. Exp. Neurol. 44 (6), 559-577.

Wright, D.J., Renoir, T., Smith, Z.M., Frazier, A.E., Francis, P.S., Thorburn, D.R., McGee, S.L., Hannan, A.J., Gray, L.J., 2015. N-Acetylcysteine improves mitochondrial function and ameliorates behavioral deficits in the R6/1 mouse model of Huntington's disease. Transl. Psychiatry 5, e492. http://dx.doi.org/10.1038/ tp.2014.131.

Zhang, S., Wang, J., Song, N., Xie, J., Jiang, H., 2009. Up-regulation of divalent metal transporter 1 is involved in 1-methyl-4-phenylpyridinium $(\operatorname{MPP}(+))$-induced apoptosis in MES23.5 cells. Neurobiol. Aging. 30 (9), 1466-1476. http:// dx.doi.org/10.1016/j.neurobiolaging.2007.11.025. 